\title{
Shape-dependent interaction of gold nanoparticles with cultured cells at laser exposure
}

\author{
O Bibikova, ${ }^{* 1,2,3,4}$ P Singh, ${ }^{5}$ A Popov, ${ }^{1,6,7}$ G Akchurin,, ${ }^{2,8}$ A Skaptsov, ${ }^{2}$ I Skovorodkin, 5 \\ V Khanadeev, ${ }^{9}$ D Mikhalevich, ${ }^{10}$ M Kinnunen, ${ }^{1}$ G Akchurin, ${ }^{2,8}$ V Bogatyrev, ${ }^{9}$ \\ N Khlebtsov, ${ }^{9,11} \mathrm{~S}$ Vainio, ${ }^{5}$ I Meglinski ${ }^{1,6,7}$ and V Tuchin ${ }^{1,2,6,8}$
}

${ }^{1}$ University of Oulu, Faculty of Information Technology and Electrical Engineering, Erkki Koiso-Kanttilan katu 3, Oulu, Finland, 90570

${ }^{2}$ Research-Education Institute of Optics and Biophotonics, Saratov National Research State University, 83 Astrakhanskaya street, Saratov 410012, Russian Federation

${ }^{3}$ Institute of Analytical and Bioanalytical Chemistry, University of Ulm, Faculty of Natural Sciences, Department of Chemistry, 11Albert-Einstein-Allee, Ulm 89081, Germany

${ }^{4}$ art photonics GmbH, Rudower Chausee 46, Berlin, Germany

${ }^{5}$ Laboratory of Developmental Biology, Center for Cell-Matrix Research, Department of Medical Biochemistry and Molecular Biology, Institute of Biomedicine, Faculty of Medicine, 5A Aapistie, Oulu 90220, Finland

${ }^{6}$ Interdisciplinary Laboratory of Biophotonics, National Research Tomsk State University, 36 Prospect Lenina, Tomsk 634050, Russian Federation

${ }^{7}$ ITMO University, 49 Kronverkskiy Prospect, St Petersburg 197101, Russian Federation

${ }^{8}$ Institute of Precision Mechanics and Control, Russian Academy of Sciences, 24 Rabochaya street, Saratov 410028, Russian Federation

${ }^{9}$ Institute of Biochemistry and Physiology of Plants and Microorganisms, Russian Academy of Sciences, 13

Prospect Entuziastov, Saratov 410049, Russian Federation

${ }^{10}$ SaratovLaser LLC, 56-5a Volskaya street, Saratov 410072, Russian Federation

${ }^{11}$ Faculty of Nano- and Biomedical Technologies, Saratov National Research State University, 83Astrakhanskaya street, Saratov 410012, Russian Federation

* E-mail: olyabibikova@ gmail.com

\begin{abstract}
Laser optoporation of cells by local heating of plasmonic gold nanoparticles (GNPs) was proven as a favorable delivery method of molecules into cells. The optoporation efficiency depends on the laser beam intensity and GNP properties. Here, we evaluate the membrane optoporation in vitro in terms of fluorescent dye permeability under treatment of a multi-pulsed nanosecond 1064-nm laser with a sharply-focused beam. Anisotropic GNPs, such as nanorods and nanostars, were fabricated to achieve the optimal GNP-cell interaction. Nanostars demonstrated highest optoporation efficacy with more than $80 \%$ of permeabilized cells within the illuminated area. By contrast to
\end{abstract}


common laser techniques, the laser beam scanning method results in cell optoporation within a controllable programmed in advance irradiated area.

Keywords: plasmon-resonant gold nanoparticles, HeLa cells, cell permeability, optoporation, laser beam scanning, nanosecond laser.

PACS: 78.67.Bf, 78.67.Qa, 87.50.cf

(Some figures may appear in color only in the online journal)

\section{Introduction}

Plasmon-resonant gold nanoparticles (GNPs) have received significant attention as a prospective technology in laser diagnostics and medicine. ${ }^{1}$ One of the novel application of GNPs is cell optoporation, a temporal perforation of cell membranes by short-pulsed laser irradiation of cells with bonded lightabsorbing micro- and nanoparticles for administration of exogenous materials into cells. ${ }^{2,3}$ This promising technique is an efficient, relatively high-throughput and virus-free method with a potential for cell transfection. ${ }^{4}$ Application of laser systems at NIR range will minimize the heat transferred by the electromagnetic wave to the cells, as well as maximize the penetration depth. Due to low absorption and scattering coefficients of biological tissues in NIR region, ${ }^{5}$ which opens up the possibility to reach underneath cells for in vivo studies. The majority of studies on optoporation has been done using gold nanospheres (NSps) with surface plasmon resonance (SPR) around $530 \mathrm{~nm}^{6}$ at visible laser shining, ${ }^{7}$ while NIR irradiation was applied in much less effective off-resonance mode. ${ }^{8,9}$ The application of anisotropic GNPs ${ }^{10}$ with SPR in NIR range will make optoporation process more effective due to precise correspondence between SPR peak position and the laser wavelength. Here, we propose and demonstrate an optimized NIR resonant optoporation of biological cells by using anisotropic nanoparticles (gold nanostars and nanorods) in combination with the pulse laser beam scanning.

\section{Methods, results and discussion}

\subsection{Gold nanoparticles characterization}

We used two types of GNPs: gold nanorods (NRs) with the length: $41 \pm 5$, diameter: $11 \pm 1 \mathrm{~nm}$ and longitudinal plasmon-resonance at $800 \mathrm{~nm}$; and gold nanostars (NSts) with tip-to-tip diameter $55 \pm 7 \mathrm{~nm}$ and plasmon-resonance at $805 \mathrm{~nm}$. NRs were prepared by the seed-mediated growth method with slight modifications, ${ }^{11}$ and gold nanostars (NSts) were synthesized with a slightly modified seed-mediated growth method as described by Yuan et al. ${ }^{12}$ with 15 -nm NSps as seeds. ${ }^{13}$ Both types of GNPs were functionalized by mPEG-SH. ${ }^{14}$

Figure 1 shows typical extinction spectra of as-prepared solutions of NRs (a), NSts (b), and their representative TEM images (inner part). The extinction of the GNP suspensions was evaluated by 
spectrophotometer system (Optronic Laboratories, USA). The size and morphology of the GNPs as retrieved by LEO 912 OMEGA microscope (Zeiss, Germany).

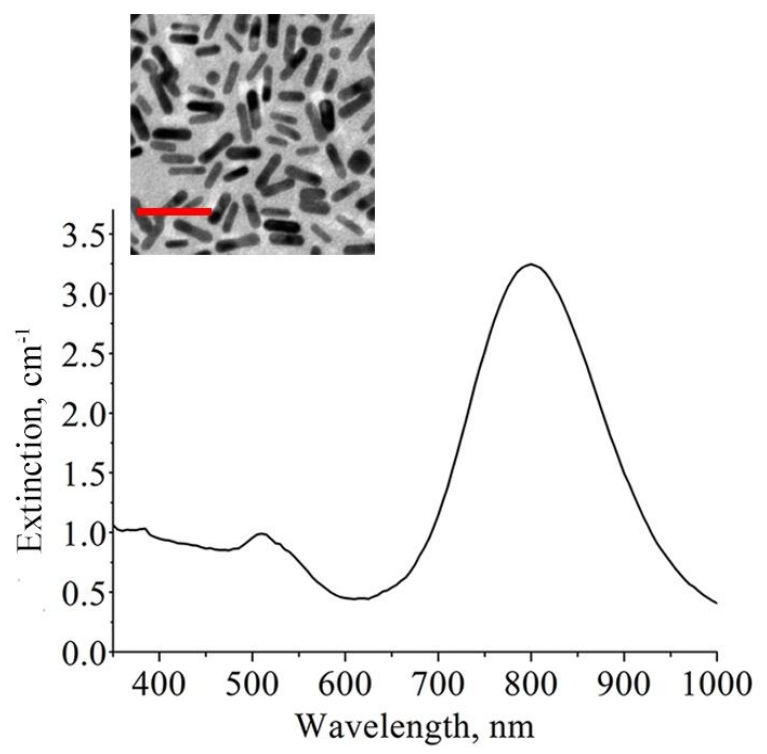

a

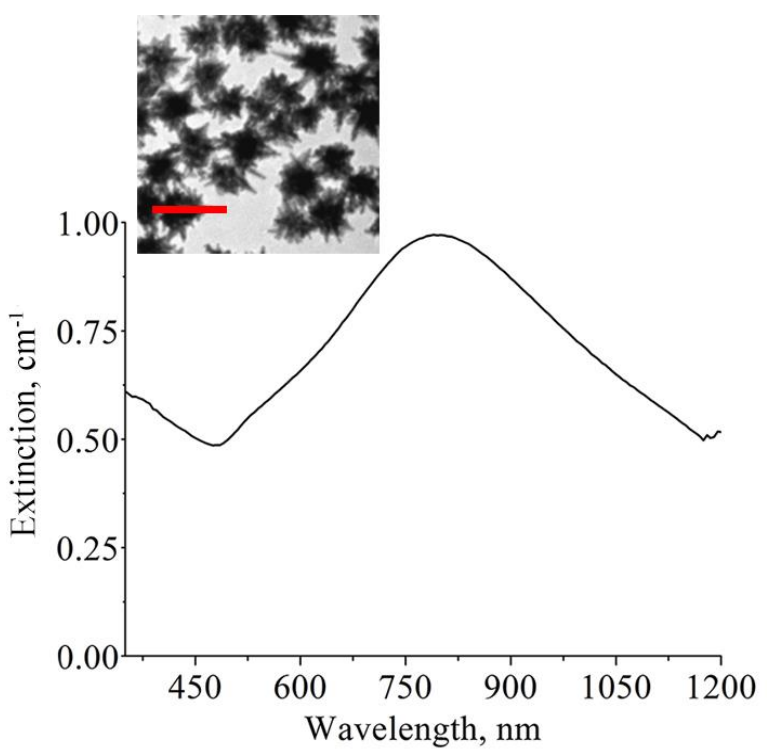

b

Figure 1 (online color at www.lasphys.com) Representative TEM images of NRs (a) and NSts (b), and extinction spectra of NRs (a), NSts (b). Scale bars are $50 \mathrm{~nm}$.

The biocompatibility of synthesized GNPs was discussed in detail in our previous paper ${ }^{15}$ and is in agreement with other examination of GNPs toxicity. ${ }^{16}$ The chosen $17 \mu \mathrm{g} / \mathrm{mL}$ concentration of GNPs was sufficient for cells perforation and was non-toxic for living cells according to previous reports [9]. It is known that the coating of GNPs with neutral PEG molecules results in weak adsorption of GNPs on the cell surface and negligible cellular uptake. Accordingly, the addition of PEG coated GNPs to the cultural medium with cells should not cause a significant GNP aggregation. To verify this assumption, we recorded differential extinction spectra of NRs after $1 \mathrm{~min}, 4 \mathrm{~h}$ and $24 \mathrm{~h}$ of incubation in cultural DMEM medium with HeLa cells. Specifically, cells had been grown to $80 \%$ of monolayer on the bottom of plate wells (figure 2). Then, the initial DMEM medium without NRs was safely replaced by DMEM medium containing NRs (the final concentration of $17 \mu \mathrm{g} / \mathrm{mL}$ ). After incubation, DMEM medium with NRs had been collected without disturbing the cell monolayer to the $1 \mathrm{~mm}$ cuvettes and differential extinction spectra had been recorded. Pure medium with cells was used as blank reference. Figure 2 clearly shows exceptional stability of NIP plasmon resonance peak for all incubation times. This observation leads to the following important conclusions. First, there is no significant aggregation of PEG-coated NRs in saltcontaining DMEM medium. Even if NRs are attached to the cell surface they act as individual particles without plasmonic coupling. Second, we can assume that NR uptake by cells is negligible as the plasmonic peak does not change its magnitude and position. This conclusion agrees with previously 
reported negligible cellular uptake for similar systems with PEG-coated NRs. ${ }^{17}$ It should be noted that the colloidal stability of PEG-coated GNPs and their weak interaction with negatively charged cells is a common property, which does not depend on a particular size and shape of GNPs. Based on obtained results, laser irradiation was carried out without removal of the particles from the medium to obtain the maximal amount of GNPs near the cell surface.

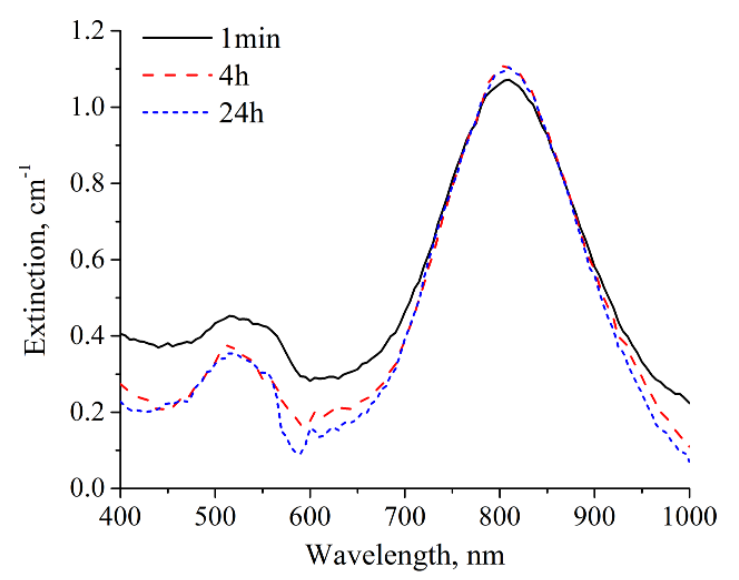

Figure 2 (online color at www.lasphys.com) Extinction spectra of NRs in DMEM medium after incubation with cells for 1 min,

$4 \mathrm{~h}, 24 \mathrm{~h}$ with the final concentration of NRs of $17 \mu \mathrm{g} / \mathrm{mL}$. Transmittance spectra were measured in a 1-mm-thick cuvette.

\subsection{Irradiation of cells by a nanosecond laser in a scanning mode}

NIR irradiation is preferable for in vivo investigations due to low scattering of tissues in the range. Here, we chose NSts and NRs with SPR in the NIR range for correspondence with an illumination laser wavelength $(1064 \mathrm{~nm})$ of scanning pulsed nanosecond ytterbium fiber laser (scan-ns-laser) (Mini Marker $2^{\mathrm{TM}}$, Laser Center, Russia) with a highly focused beam with the diameter of $6 \mu \mathrm{m}$. Irradiation parameters for laser system are presented in Table.

Table 1. Irradiation parameters and optoporation effectiveness: ${ }^{a}$

\begin{tabular}{c|c|c|c|c|c|c|c|c|c}
\hline$\lambda, \mathrm{nm}$ & $\tau, \mathrm{ns}$ & $P, \mathrm{~W}$ & $f_{\mathrm{p}}, \mathrm{kHz}$ & $E_{\mathrm{p}}, \mathrm{mJ}$ & $v, \mathrm{~m} / \mathrm{s}$ & $\omega, \mu \mathrm{m}$ & $I, \mathrm{~W} / \mathrm{cm}^{2}$ & $t, \mathrm{sec}$ & $N$ \\
\hline 1064 & 4 & 20 & 20 & 1 & 0.4 & 6 & 0.56 & $2 *$ & $4 \times 10^{4}$ \\
\hline
\end{tabular}

a $\lambda$ is the irradiation wavelength, $\tau$ is the pulse duration, $P$ is mean power, $f_{\mathrm{p}}$ is the pulse repetition rate, $E_{\mathrm{p}}$ is the maximum output pulse energy, $v$ is the scanning speed, $\omega$ is the spot size, $I$ is the mean power density, $t$ is the exposure time, $N$ is the total number of laser pulses within a single focal plane, $\mathrm{c}$ is the $\mathrm{Au}$ concentration, *Full time of irradiation during a single focal plane scanning, step $20 \mu \mathrm{m}$ and 1 pulse per step.

It is known that excessive radiation power causes melting of GNPs and breaking them up into smaller fragments [8]. To control the melting effect, we measured the extinction spectra of NSts as the most sensitive GNPs for environmental variation, before and after laser irradiation with the different pulse 
energy. To obtain irradiation of the whole NSts volume, we placed NSts suspensions $(17 \mu \mathrm{g} / \mathrm{mL})$ in the 96-well plate and scanned point by point in line mode within horizontal XY focal plane $4 \times 4 \mathrm{~mm}^{2}$ covered the whole surface of a single well in the plate. Irradiation parameters shown in Table. The scanning depth was $2 \mathrm{~mm}$, with the distance between adjacent points in XY focal plane of $20 \mu \mathrm{m}$ and distance between horizontal scans of $20 \mu \mathrm{m}$ as well. Energy of a single pulse was $1 \mu \mathrm{J}$ and $10 \mu \mathrm{J}$. After irradiation, extinction of each sample was measured in a 1-mm-thick cuvette. Figure 3 shows spectra of NSts without irradiation; and after irradiation with a single pulse energy of $1 \mu \mathrm{J}$ and $10 \mu \mathrm{J}$, as well as TEM images of non-irradiated and irradiated NSts.
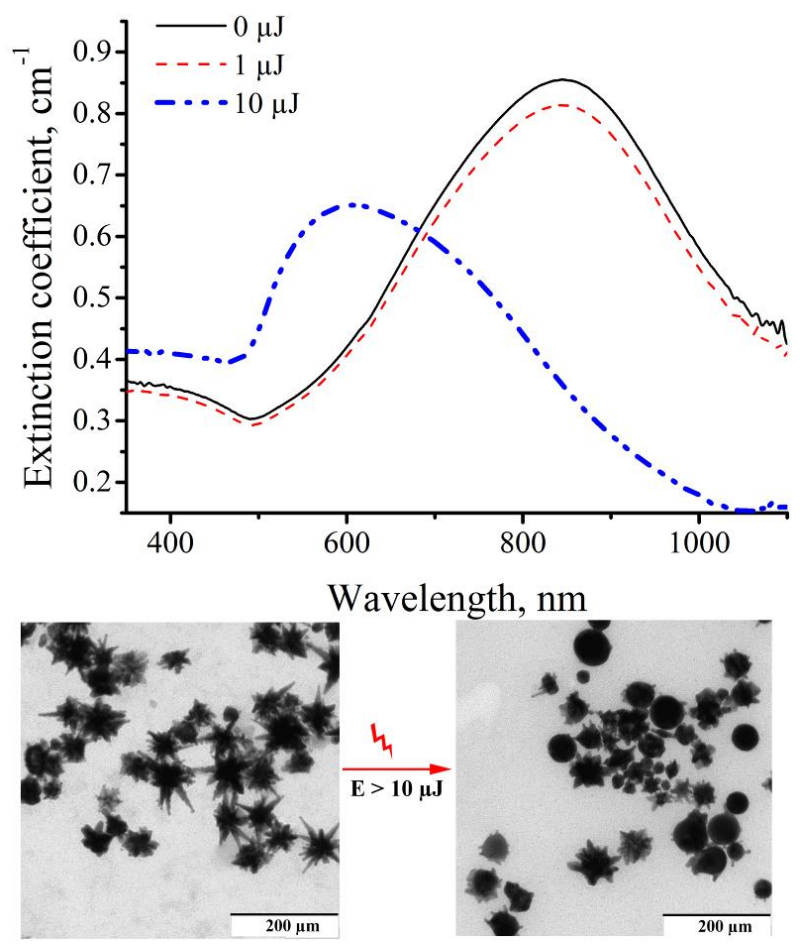

Figure 3 (online color at www.lasphys.com) Spectra and TEM images of non-irradiated and irradiated (NStsuspension by the scan-ns-laser (1064 nm). The energy of a single pulse: $0 \mu \mathrm{J} ; 1 \mu \mathrm{J}, 10 \mu \mathrm{J}$. The total number of laser pulses for one focal plane is $4 \times 10^{4}$.

The extinction spectrum of NSts after irradiation with a laser pulse energy of $1 \mu \mathrm{J}$ remains unchanged, which proves the absence of particle melting and fragmentation upon this irradiation. The transformation of GNPs shape under nano-pulse irradiation (from $\mu \mathrm{J}$ to $\mathrm{mJ}$ ) was demonstrated for gold nanorods ${ }^{18}$ and nanostars ${ }^{19}$ by use of TEM and optical absorption. In both cases, the authors showed transformation of GNPs to nanospheres.

Based on these results, we explored the scan-ns-laser with the single pulse energy ranging from 0.1 to $1 \mu \mathrm{J}$ for cell optoporation. Taking into account a $20-\mu \mathrm{m}$ diameter of a single HeLa cell, we added DMEM medium with layer thickness over cells nearly $2 \mathrm{~mm}$, then focused the laser beam on cell layer, $2 \mathrm{~mm}$ 
below the medium surface. The exposed area of $4 \times 4 \mathrm{~mm}^{2}$ was scanned point by point in line mode with a scanning parameters shown in Table, with the distance between single laser beam positions of $20 \mu \mathrm{m}$, and 1 pulse per beam position. The GNPs concentration was $17 \mu \mathrm{g} / \mathrm{mL}$. Cells incubated with GNPs without irradiation and pure cells under laser treatment were used as negative controls. We added propidium iodide (PI) to the cell suspensions before irradiation to mark perforated cells membranes due to the laser treatment. After the laser irradiation, cells were washed immediately to remove the remaining extracellular PI to avoid its uptake by endocytosis. Temperature of medium was recorded by Thermal Camera (Irisys, UK). At irradiation, the temperature of cell suspensions with or without GNPs was lower than $30^{\circ} \mathrm{C}$. The studies of laser interaction with GNPs was attracted significant interest, ${ }^{20,21}$ moreover, absence of heating of surrounding medium also was proved theoretically by Avetisyan et al. ${ }^{22}$ for $800-\mathrm{nm}$ pulsed (50 ps - $50 \mathrm{~ns}$ ): the calculated temperature on the surface can be up to $100^{\circ} \mathrm{C}$, while $10 \mathrm{~nm}$ away from the surface in water it hardly reaches $50^{\circ} \mathrm{C}$.

Preparations of cells were observed by inverted microscope Leica 3000 (Leica Microsystems, Germany) in the fluorescence mode (filter I3, excitation 450-490 nm) at the Simbioz Center, IBPPM RAS, Saratov. Each experiment was triplicated. Figure 4 shows combined bright-field and fluorescent images of living cells: non-irradiated control samples and samples of cells incubated with NRs and NSts (upper row); samples irradiated with pulse energy $0.1 \mu \mathrm{J}$ (lower row).

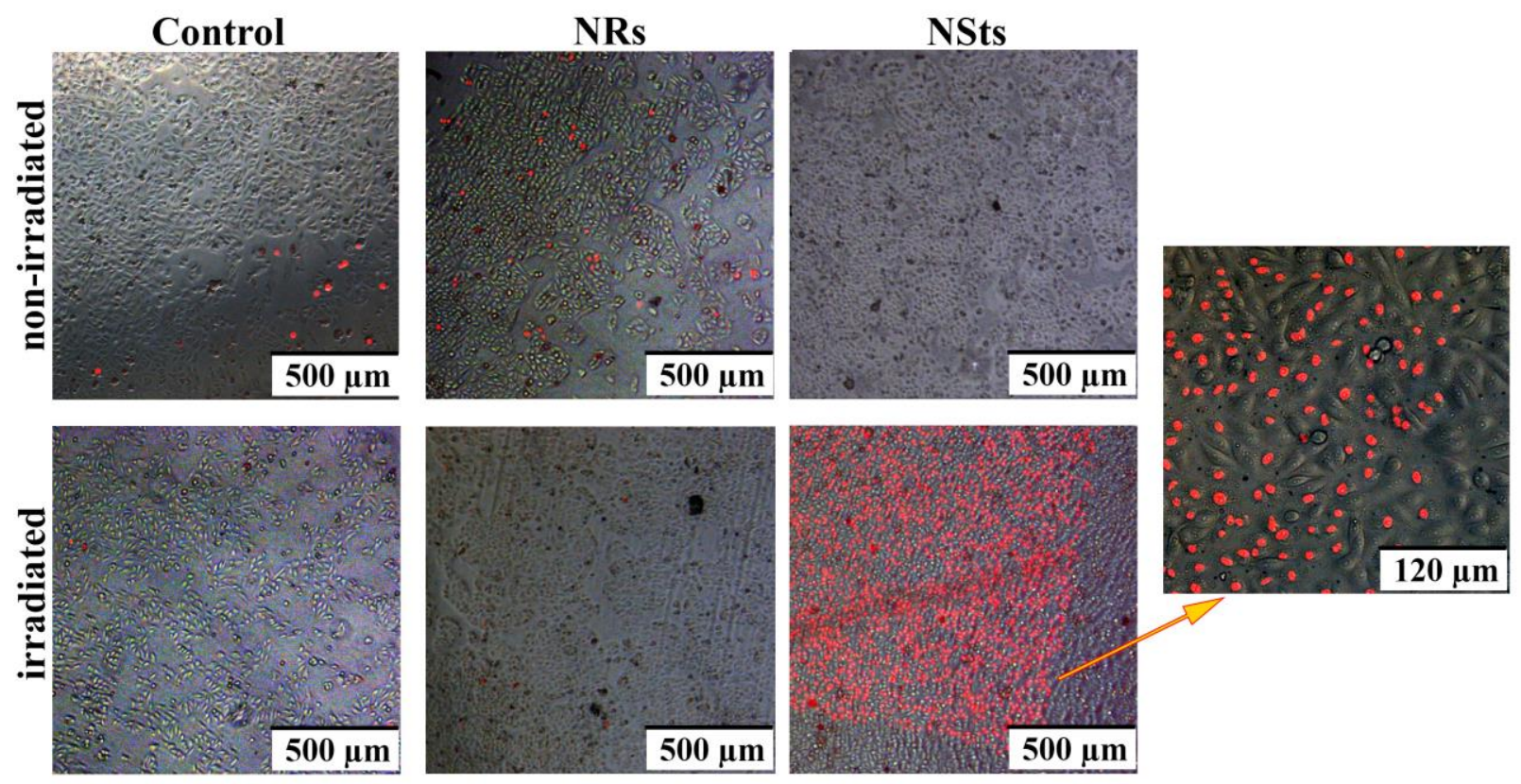

Figure 4 (online color at www.lasphys.com) Combined bright-field and fluorescent images of control samples and samples incubated with $17 \mu \mathrm{g} / \mathrm{mL}$ NRs and NSts. Upper panel: non-irradiated cell suspensions; lower panel: samples irradiated by scan-ns-laser. View with higher magnification demonstrates the birder between irradiated and non-irradiated cells with NSts. Cells were irradiated with a single pulse energy $0.1 \mu \mathrm{J}$, scanning speed $0.4 \mathrm{~m} / \mathrm{s}$, 
distance between single laser beam positions $20 \mu \mathrm{m}, 1$ pulse per beam position. Size of horizontal exposed area was of $4 \times 4 \mathrm{~mm}^{2}$, time of exposure was $2 \mathrm{~s}$.

We observed no perforation of cell membrane mediated by NRs neither under irradiation of $0.1 \mu \mathrm{J}$, neither under $1 \mu \mathrm{J}$ (data not shown). The amount of PI-positive cells incubated with NRs (5\%) in the irradiated sample equals irradiated control sample without GNPs (6\%). The lack of membrane permeabilization can be explained by the relatively narrow peak of NRs (the significant extinction values lies between 650 and $950 \mathrm{~nm}$ ) and aggregation stability due to PEG functionalization. The optoporation effect was much more pronounced for NSts under the same irradiation conditions. The border between treated and untreated cells incubated with NSts is clearly seen. Inside the irradiated area, $80 \%$ of cells were PI-positive. Only 4\% of PI-positive cells were observed in the untreated samples incubated with NSts. Much more effective permeabilization ability of cells incubated with NSts compared with cells in presence of NRs can be explained by the NSts broad spectra; on this case, on the laser irradiation wavelength $1064 \mathrm{~nm}$ absorption is still high for efficient optoporation, as well as by their polarization and orientation isotropy. Such a result shows that nanosecond laser scanning of certain area of cell layer provide accurate drive for the transport of the PI molecules into cells exactly in the treated area. Owing to a broadened SPR, NSts are most preferable as plasmonic labels for this type of laser treatment. In future studies, the delivery of extracellular material through cell membranes might be a valuable alternative, for gene therapeutic approaches and transfection.

\section{Conclusion}

We have proposed and demonstrated an optimized NIR resonant optoporation of biological cells by using gold nanostars in combination with the laser beam scanning. The use of nanosecond laser working in a scanning mode ensures precise control for GNP-mediated optical cell permeabilization. In particular, the perforated cells were presented within the irradiated area only. Gold nanostars are shown to be more effective optoporation agents than gold nanorods. The obtained results can be useful for further development of GNP-mediated optoporation technology, which combines precise spatial and temporal control for laser irradiation with high optoporation efficiency and small side temperature effects. These properties are promising for possible applications to delivery of transfection substances into cells.

\section{Acknowledgements}

This study was supported by the Infotech Oulu Graduate School and the Opto-Electronics and Measurement Techniques Research Unit of the University of Oulu, Finland; the Russian Science Foundation, project no. 14-15-00186 and no. 14-13-01167 (the work by VK, VB, and NK). Authors 
greatly appreciate the members of Center of Microscopy and Nanotechnology for the guidance and help. Authors are thankful to Risto Myllyla for his support and encouragement.

\section{References}

${ }^{1}$ E. C. Dreaden, A.M. Alkilany, X. Huang, C. J. Murphy, M. A. El-Sayed, "The golden age: gold nanoparticles for biomedicine," Chem. Soc. Rev. 41, 2740-2779 (2012).

${ }^{2}$ C. Yao, Z. Zhang, R. Rahmanzadeh, G. Hüttmann, "Laser-based gene transfection and gene therapy,” IEEE Trans. Nanobiosci. 7(2), 111-119 (2008).

${ }^{3}$ Y.-C. Wu, T.-H. Wu, D. L. Clemens, B.-Y. Lee, X. Wen, M. A. Horwitz, M. A. Teitell, P.-Y. Chiou, "Massively parallel delivery of large cargo into mammalian cells with light pulses," Nat. Methods 12(5), 439-444 (2015).

${ }^{4}$ M. Schomaker, D. Killian, S. Willenbrock, D. Heinemann, S. Kalies, A. Ngezahayo, I. Nolte, T. Ripken, C.

Junghanß, H. Meyer, E. H. Murua, A. Heisterkamp, "Biophysical effects in off-resonant gold nanoparticle mediated (GNOME) laser transfection of cell lines, primary- and stem cells using fs laser pulses," J. Biophotonics 8(8), 646658 (2015).

${ }^{5}$ A. N. Bashkatov, E. A. Genina, V. I. Kochubey, and V. V. Tuchin, "Optical properties of human skin, subcutaneous and mucous tissues in the wavelength range from 400 to $2000 \mathrm{~nm}$," J. Phys. D Appl. Phys. 38(15), 2543-2555 (2005).

${ }^{6}$ A. Lemelle, B. Veksler, I.S. Kozhevnikov, G.G. Akchurin, S.A. Piletsky, I. Meglinski "Application of gold nanoparticles as contrast agents in confocal laser scanning microscopy,” Laser Phys. Lett. 6 (1), 71-75 (2009)

${ }^{7}$ K. Bhattacharyya, S. Mehta, J. Viator, "Optically absorbing nanoparticle mediated cell membrane permeabilization," Opt. Lett. 37(21), 4474-4476 (2012).

${ }^{8}$ M. Schomaker, D. Heinemann, S. Kalies, S. Willenbrock, S. Wagner, I. Nolte, T. Ripken, H.M. Escobar, H. Meyer, A. Heisterkamp, "Characterization of nanoparticle mediated laser transfection by femtosecond laser pulses for applications in molecular medicine," J. Nanobiotecnology 13(10), 1-15 (2015).

${ }^{9}$ B.L. Lalonde, E. Boulais, J.-J. Lebrun, M. Meunier, "Visible and near infrared resonance plasmonic enhanced nanosecond laser optoporation of cancer cells," Biomed. Opt. Express 4(4), 490-499 (2013).

${ }^{10}$ Ch.-Ch. Chen, Y.-P. Lin, Ch.-W. Wang, H.-Ch. Tzeng, Ch.-H. Wu, Y.-Ch. Chen, Ch.-P. Chen, L.-Ch. Chen, Y.$\mathrm{Ch} . \mathrm{Wu}$, "DNA-gold nanorod conjugates for remote control of localized gene expression by near infrared irradiation," J. Am. Chem. Soc. 128(11), 3709-3715 (2006)

${ }^{11}$ B. Khlebtsov, V. Khanadeev, T. Pylaev, N. Khlebtsov, "New T-matrix solvable model for nanorods: TEM-based ensemble simulations supported by experiments," J. Phys. Chem. C 115(14), 6317-6323 (2011).

${ }^{12}$ H. Yuan, C. G. Khoury, H. Hwang, Ch. M. Wilson, G. A. Grant, T. Vo-Dinh, "Gold nanostars: surfactant-free synthesis, 3D modelling, and two-photon photoluminescence imaging," Nanotechnology 23(7), 075102 (2012).

${ }^{13}$ K. C. Grabar, R. G. Freeman, M. B. Hommer, M. J. Natan, "Preparation and characterization of Au colloid monolayers," Anal. Chem. 67(4) 735-743(1995).

${ }^{14}$ B. Khlebtsov, Khanadeev, V., Khlebtsov, N. "Tunable depolarized light scattering from gold and gold/silver nanorods," Phys. Chem. 12(13), 3210-3218 (2010).

${ }^{15}$ O. Bibikova, A. Popov, A. Bykov, A. Prilepskii, M. Kinnunen, K. Kordas, V. Bogatyrev, N. Khlebtsov, S. Vainio, V. Tuchin, "Optical properties of plasmon-resonant bare and silica-coated nanostars used for cell imaging," J. Biomedical Optics 20(7), 076017 (2015)

${ }^{16}$ N. Khlebtsov, L. Dykman, "Biodistribution and toxicity of engineered gold nanoparticles: a review of in vitro and in vivo studies," Chem. Soc. Rev. 40(3), 1647-1671 (2011).

${ }^{17}$ P. Pallavicini, E. Cabrini, G. Cavallaro, G. Chirico, M. Collini, L. D'Alfonso, G. Dacarro, A. Donà, N. Marchesi, C. Milanese, A. Pascale, L. Sironi, T. Angelo, "Gold nanostars coated with neutral and charged polyethylene glycols: A comparative study of in vitro biocompatibility and of their interaction with SH-SY5Y neuroblastoma cells," J. Inorg. Biochem. 151, 123-131 (2015).

${ }^{18}$ S. Link, C. Burda, M. B. Mohamed, B. Nikoobakht, M. A. El-Sayed, "Laser photothermal melting and fragmentation of gold nanorods: energy and laser pulse-width dependence," J. Phys. Chem. A, 103(9) 1165-1170 (1999).

${ }^{19}$ S. Trigari, A. Rindi, G. Margheri, S. Sottini, G.Dellepiane, E. Giorgetti, "Synthesis and modelling of gold nanostars with tunable morphology and extinction spectrum," J. Mater. Chem., 21, 6531-6540 (2011). 
${ }^{20}$ V.K. Pustovalov, V.A. Babenko, "Optical properties of gold nanoparticles at laser radiation wavelengths for laser applications in nanotechnology and medicine," Laser Phys. Lett., 1(10), 516-520 (2004).

${ }^{21}$ N. Kroó, P. Rácz, "Plasmonics - the interaction of light with metal surface electrons," Laser Phys, 26, 084011 (2016)

${ }^{22}$ Y. A. Avetisyan, A. N. Yakunin, V. V. Tuchin, "Novel thermal effect at nanoshell heating by pulsed laser irradiation: Hoop-shaped hot zone formation," J. Biophotonics 5(10), 734-744 (2012). 